\title{
RETRACTION: Pain in systemic sclerosis
}

June, 2018

\footnotetext{
T
}

o our readers:

With deep regrets, we inform that the article Pain in systemic sclerosis (DOI: https:// doi.org/10.4081/reumatismo.2014.764), which has been published in Reumatismo (2014; 66(1): 44-47), contains verbatim text plagiarized from another paper (1).

The manuscript must be considered as retracted.

On behalf of the Editorial Board of Reumatismo, I apologize to the Author of the manuscript whose text was plagiarized by Stisi et al. that this was not picked up in the peer review process. I also apologize to the affected journal for the violation of copyright due to plagiarism.

Reumatismo is uncompromising in its commitment to scientific integrity. When credible evidence of misconduct is brought to our attention, our commitment to the scientific record and to our readership requires immediate notification.

Reumatismo is increasingly employing sophisticated software to detect plagiarism. Other journals use similar tools. Authors should be aware that most journals routinely employ plagiarism detection software, and that any plagiarism is likely to be detected.

Marco A. Cimmino

Editor-in-Chief Reumatismo

Corresponding author: Marco A. Cimmino Clinica Reumatologica, DIMI Viale Benedetto XV, 6 16132 Genova, Italia E-mail: cimmino@unige.it

\section{REFERENCES}

1. Merz EL, Malcarne VL, Assassi S, et al. Biopsychosocial typologies of pain in a cohort of patients with systemic sclerosis. Arthritis Care Res (Hoboken). 2014; 66: 567-74. 